\title{
Aortic valve papillary fibroelastoma causing embolic strokes: a case report and review
}

This article was published in the following Dove Press journal:

International Medical Case Reports Journal

29 March 2017

Number of times this article has been viewed

\author{
Avraham Miller' \\ Audrik Perez' \\ Swathi Pabba ${ }^{2}$ \\ Vijay Shetty ${ }^{3}$ \\ 'Internal Medicine, Maimonides \\ Medical Center, Brooklyn, NY, USA; \\ ${ }^{2}$ Chalmeda Anand Rao Institute \\ of Medical Sciences, Telangana, \\ India; ${ }^{3}$ Department of Cardiology, \\ Maimonides Medical Center, Brooklyn, \\ NY, USA
}

\begin{abstract}
Papillary fibroelastomas (PFEs) are the second most common benign neoplasms of the cardiac valves and are being recognized more frequently because of higher resolution imaging technology. PFEs are associated with substantial complications that are secondary to systemic embolism. Surgical resection should be offered to all patients who have symptoms and to asymptomatic patients who have pedunculated lesions or tumors larger than $1 \mathrm{~cm}$ in diameter. Herein, we present a patient who presented for a second time in 2 months with stroke symptoms. During his first admission, a transthoracic echocardiogram was performed and he was sent home after resolution of his symptoms and a grossly negative workup. During his second admission, a transesophageal echocardiogram was performed and the PFE was found and later excised. While this discussion reviews the literature with regard to detection and management, it will hopefully serve as a reminder to keep this on the differential when the workup has remained without an obvious source.
\end{abstract}

Keywords: stroke, fibroelastoma, papillary, embolism

\section{Introduction}

Primary cardiac tumors are rare. Papillary fibroelastomas (PFEs) are frondlike papillary growths that typically occur on the cardiac valves but can also be found on the papillary muscles, chordae tendenae, the ventricular septum, or the endocardial surface. ${ }^{1}$ The prevalence of primary cardiac tumors range from $0.0017 \%$ to $0.28 \%$, but they are the second most common benign neoplasm of the cardiac valves after myxomas. ${ }^{2}$ Their prompt detection is of great importance as they are the potential causes of systemic emboli, stroke, myocardial infarction, and sudden death. We present a case of a PFE causing two embolic strokes, reminding us of the importance of keeping this as an important differential when determining the cause of shower emboli in an otherwise negative workup.

\section{Case description}

The patient was a 64-year-old male with a past medical history of hypertension and coronary artery disease and is currently a 1 pack per day smoker and has been recently treated for transient ischemic attack 2 months prior. He presented with new onset aphasia and unsteady gait for 2-3 days. Upon arrival to the emergency department, he was found to be afebrile with a heart rate of $48-54 \mathrm{bpm}$, a respiratory rate of $18 \mathrm{bpm}$, and a blood pressure of 142/66 mm Hg.
Correspondence: Avraham Miller Internal Medicine, Maimonides Medical Center, 4802 10th Ave, Brooklyn, NY II 219 , USA

Tel +l 7282836000

Email avmiller@maimonidesmed.org 
On examination, the patient was awake, alert, and oriented. His speech was clear and slightly hesitant, but without dysarthria. He followed commands and was able to name objects. There was no facial weakness or asymmetry. Other than some mild right upper extremity ataxia on the fingerto-nose test, the rest of the neurological examination was within normal limits.

Our stroke team was immediately called and they recommended imaging studies of the head. A computed tomography scan of the head without contrast showed no acute intracranial disease. Magnetic resonance imaging of brain showed multiple areas of restricted diffusion in the left middle cerebral artery territory in the medial and lateral left temporoparietal cortex and subcortical and periventricular white matter consistent with acute hemorrhagic infarcts, probably embolic. There were also multiple areas of restricted diffusion in the left frontoparietal periventricular centrum semiovale region consistent with acute watershed infarcts (Figures 1 and 2). The patient was immediately started on aspirin, high-dose statin, clopidogrel, and fluids to allow for permissive hypertension.

As part of the workup to determine the cause of his embolic stroke, the patient would have been sent for a transthoracic echocardiogram (TTE), but since he was recently worked up for a stroke just 2 months prior to this admission with a TTE, he was sent for a transesophageal echocardiogram (TEE). The TEE showed a fairly large $(12 \times 3 \mathrm{~mm})$, bulky, and highly mobile mass on the aortic aspect of the aortic valve, consistent with a fibroelastoma (Figures 3 and 4).

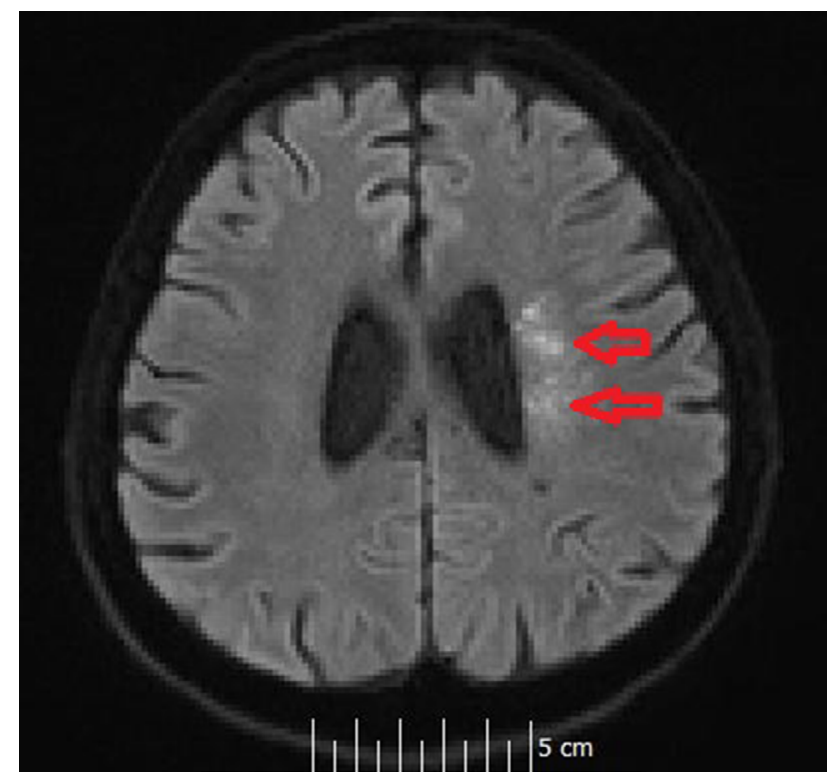

Figure I Multiple areas of restricted diffusion in the left MCA territory. Note: The arrows represent the areas of hypodensity which were read as acute stroke.

Abbreviation: MCA, middle cerebral artery.

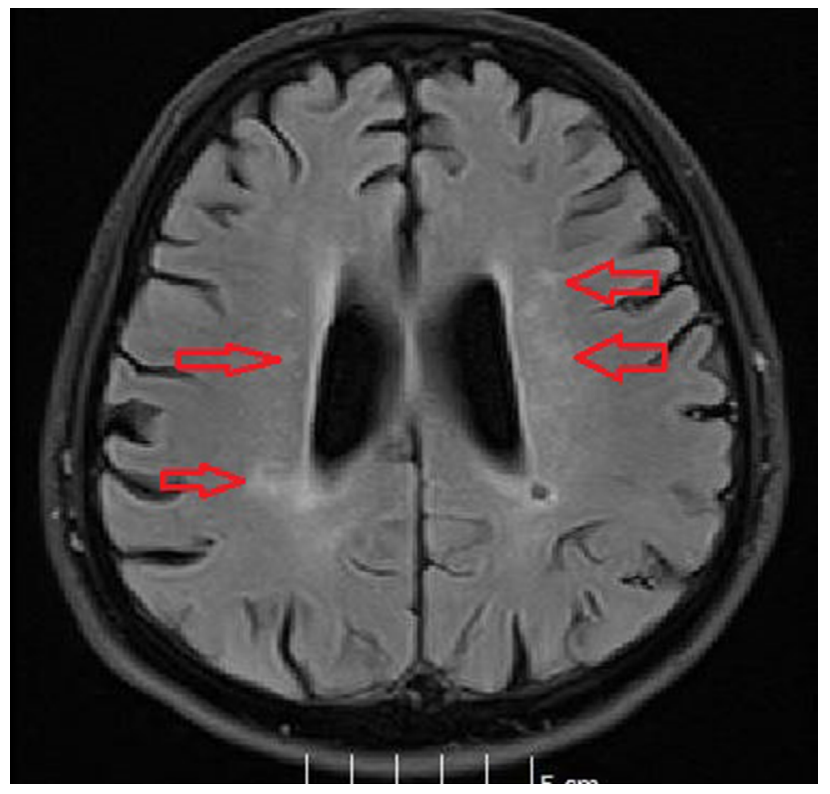

Figure $\mathbf{2}$ Chronic small infarct in the right parietal periventricular white matter. Note: The arrows represent areas of hypodensity which were read as acute stroke.

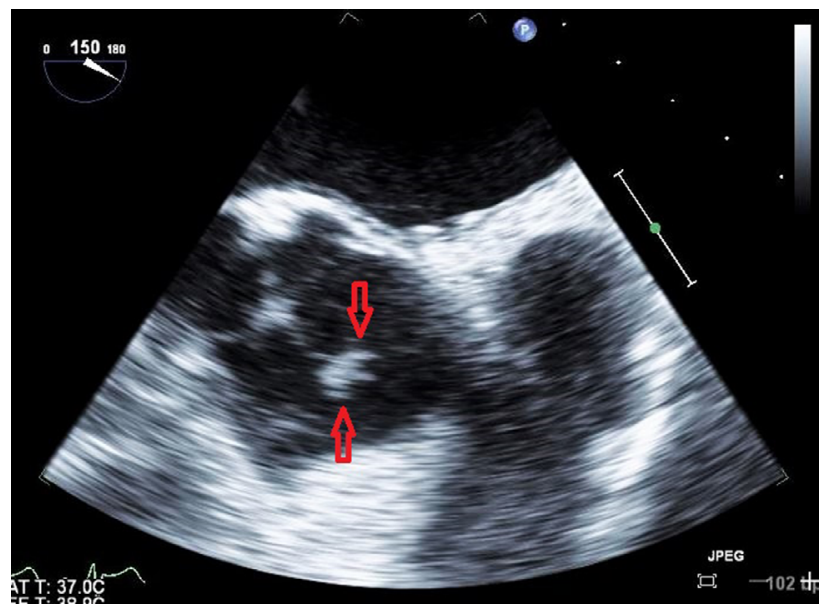

Figure 3 Fronds branching off the pedunculated PFE.

Notes: The red arrows represent the tip of the valve where the fibroelstoma is located. The image shows the fibroelastoma is open and wide.

Abbreviation: PFE, papillary fibroelastoma.

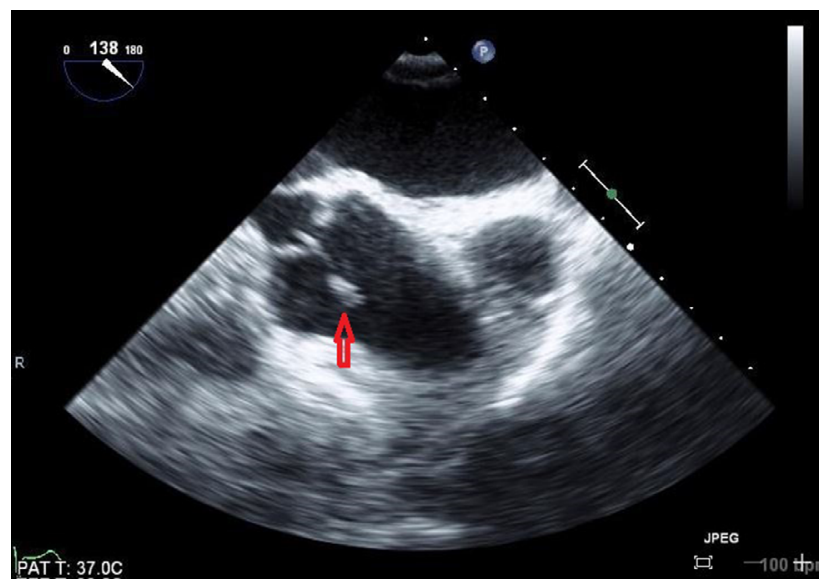

Figure 4 Picture depicts just how the structure moves when the valves open. Note: The arrows represent the fibroelastoma in a closed and smaller position. 
After completing the rest of the workup, it was determined that this was likely the cause of his stroke. Cardiothoracic surgery was consulted for removal of the growth. Because of recent Plavix ${ }^{\circledR}$ (Clopidogrel; Bristol-Myers Squibb, New York, NY, USA) use, the surgery was postponed for a couple of days while he remained on heparin. Surgery was able to remove the growth using a minimally invasive hemisternotomy approach with only 66 minutes of bypass time. The patient's postoperative course was smooth with only some mild hypertension postprocedure. Otherwise, the patient's neurological status returned back to normal and he continues to improve with intensive physiotherapy.

The Maimonides Medical Center (MMC) IRB decided that neither IRB approval nor a Health Insurance Portability and Accountability Act of 1996 (HIPAA) Waiver/HIPAA Authorization required for case report that involves no more than three patients, provided the presentation or publication does not have identifiable information and the activity is not considered FDA regulated research.

\section{Discussion}

PFEs are rare, benign primary cardiac tumors. Their nomenclature have sometimes been confusing as several names have been used to identify them in the past, but PFE is the most widely accepted name. ${ }^{3,4}$ They are considered the most frequent primary cardiac tumor originating from the valvular endocardium. The valvular distribution predominates on the left side of the heart, with $29 \%$ of the cases on the aortic valve, $25 \%$ on the mitral valve, $17 \%$ on the tricuspid valve, and $13 \%$ on the pulmonary valve. ${ }^{1}$ PFEs are characteristically small avascular solitary tumors with multiple arms that resemble the sea anemone. ${ }^{5}$

Several mechanisms behind the development of PFEs exist, but none have been scientifically proven. The most commonly accepted explanation for its origin is the microthrombus theory, which hypothesizes that they originate as small thrombi that coalesce on the coopting margins of the valve at the site where some minor endothelial damage may have occurred previously. ${ }^{6}$ PFEs resemble chordae tendineae and have two layers, an outer hyperplastic endothelial layer and a dense central core, that are contiguous with the valve leaflet. Their surface is covered with numerous filiform projections with an intermediate layer of loose, mucopolysaccharide-rich connective tissue, which is sandwiched between the outer endothelium and the central core. The central core contains an acellular fibrous axis that forms a concentric granular pattern with layers of fibrin and a mucopolysaccharide matrix that is usually acidic.?

The clinical presentation of PFEs can vary between being asymptomatic to symptomatic based on the consequences of severe thromboembolic complications such as myocardial infarction and stroke. Pulmonary embolism, congestive heart failure, near syncope, ventricular fibrillation, and sudden death, while rare, have also been reported. ${ }^{1,8}$ The embolic potential of the tumor results from fragmentation of the papillary spikelets or even from thrombi formed by platelets and fibrin, which occasionally adhere to the surface of the tumor as is also thought to be the mechanism for stroke in cases of cardiac myxomas. ${ }^{9}$ Most PFEs are located on the left side of the heart, which increases the risk of systemic embolization. ${ }^{10}$ In reality, an embolic cerebral stroke in a young patient with no evidence of cerebrovascular disease, particularly in the presence of sinus rhythm, should prompt investigation into the presence of a cardiac tumor along with infective endocarditis and mitral valve prolapse. ${ }^{11}$

In 2016, Saver $^{12}$ published a review in which he defined cryptogenic strokes as strokes with an unidentified cause following standard evaluation. The purpose for trying to go beyond the standard evaluation to figure out a cause has to do with recurrence rate. Most studies regarding cryptogenic stroke show that they come with a low recurrence rate. In one study, the recurrence rate was $1.9 \%$ in the first year following the stroke, and $0.8 \%$ per year in years $2-4 .{ }^{13}$ Because of the impact on recurrence, all efforts should be made to try and identify the source of an embolic stroke prior to labeling them as cryptogenic. In our patient, the presentation of a second episode of stroke-like symptoms within 2 months prompted a more thorough workup given the evidence of an embolic source seen on magnetic resonance imaging. As a TTE was performed as part of the workup during his initial presentation, our patient was sent straight for the TEE for a better look at the valves and cardiac chambers. It was only with this - a more thorough look - that the PFE was found, prompting immediate surgical removal.

As with PFEs, ischemic cerebral infarction is one of the most common as well as serious presentations of cardiac myxoma. ${ }^{14}$ However, there are no clear guidelines for immediate medical management following stroke due to atrial myxoma. The treatment of acute ischemic strokes caused by embolic atrial myxoma is controversial, largely because the embolus could be composed of the tumor itself or thrombus, adhered thrombotic material, or a combination of both. ${ }^{15}$ It is reasonable to argue that the best possible course of action is thrombolytic therapy, depending on the composition of the emboli. Studies have reported that patients with sudden cerebral infarction associated with myxoma in whom thrombolytic therapy was highly effective and pathologic findings suggest thrombotic embolism are increasing. ${ }^{16}$ However, it remains difficult to draw a firm conclusion from 
the paucity of existing data, which consists of single-case reports employing a variety of methods. Therefore, once the diagnosis of a PFE is established, prophylactic intravenous anticoagulation should be initiated, to guard against thrombi until surgical resection is accomplished, as was performed with our patient in the form of therapy with heparin. The optimal surgical procedure for pedunculated tumors is valvesparing resection of the tumor. More than $80 \%$ of aortic valve PFEs can be treated only with shave excision. ${ }^{17}$ Aortic valve resection or replacement is generally not needed unless there is underlying degeneration or extensive destruction of the native valve. Evidence from TEE follow-up studies suggest that the incidence of recurrence is very low. ${ }^{18}$

\section{Disclosure}

The authors report no conflicts of interest in this work.

\section{References}

1. Grinda JM, Couetil JP, Chauvaud S, et al. Cardiac valve papillary fibroelastoma: surgical excision for revealed or potential embolization. J Thorac Cardiovasc Surg. 1999;117:106-110.

2. Law KB, Phillips KR, Cusimano RJ, Butany J. Multifocal "tapete" papillary fibroelastoma. J Clin Pathol. 2009;62:1066-1070.

3. Lichtenstein HL, Lee JC, Stewart S. Papillary tumor of the heart: incidental finding at surgery. Hum Pathol. 1979;10:473-475.

4. Shahian DM, Labib SB, Chang G. Cardiac papillary fibroelastoma. Ann Thorac Surg. 1995;59:538-541.
5. Giuliani ER, Gersh BJ, McGoon MD, Hayes DL, Schaff HV. Mayo Clinic Pratice of Cardiology. 3rd ed. New York: Mosby; 1996.

6. Magarey FR. On the mode of formation of Lambl's excrescences and their relation to chronic thickening of the mitral valve. J Pathol Bacteriol. 1949;61(2):203-208.

7. Chitwood WR Jr. Cardiac neoplasms: current diagnosis, pathology, and therapy. J Card Surg. 1988;3(2):119-154.

8. Gopaldas RR, Atluri PV, Blaustein AS, Bakaeen FG, Huh J, Chu D. Papillary fibroelastoma of the aortic valve-operative approaches upon incidental discovery. Tex Heart Inst J. 2009;36(2):160-163.

9. Wold LE, Lie JT. Cardiac myxomas: a clinicopathologic profile. Am J Pathol. 1980;101:219-240.

10. Mezilis NE, Dardas PS, Tsikaderis DD, et al. Papillary fibroelastoma of the cardiac valves: a rare cause of embolic stroke. Hellenic J Cardiol. 2005;46(4):310-313.

11. Daniel WG, Mugge A. Transesophageal echocardiography. $N$ Engl $J$ Med. 1995;332: 1268-1279.

12. Saver JL. Cryptogenic stroke. N Engl J Med. 2016;374:2065-2074.

13. Mas JL, Arquizan C, Lamy C, et al. Recurrent cerebrovascular events associated with patent foramen ovale, arial septal aneurysm, or both. N Engl J Med. 2001;345:1740-1746.

14. Lee VH, Connolly HM, Brown RD Jr. Central nervous system manifestations of cardiac myxoma. Arch Neurol. 2007;64(8):1115-1120.

15. Burke AP, Virmani R. Cardiac myxoma. A clinicopathologic study. Am J Clin Pathol. 1993;100(6):671-680.

16. Acampa M, Guideri F, Tassi R, et al. Thrombolytic treatment of cardiac myxoma-induced ischemic stroke: a review. Curr Drug Saf. 2014; $9(2): 83-88$.

17. Westhof FB, Chryssagis K, Liangos A, Batz G, Diegeler A. Aortic valve leaflet reconstruction after excision of a papillary fibroelastoma using autologous pericardium. Thorac Cardiovasc Surg. 2007;55(3):204-207.

18. Sun JP, Asher CR, Yang XS, et al. Clinical and echocardiographic characteristics of papillary fibroelastomas: a retrospective and prospective study in 162 patients. Circulation. 2001;103(22):2687-2693.
International Medical Case Reports Journal

\section{Publish your work in this journal}

The International Medical Case Reports Journal is an international, peer-reviewed open-access journal publishing original case reports from all medical specialties. Previously unpublished medical posters are also accepted relating to any area of clinical or preclinical science. Submissions should not normally exceed 2,000 words or

\section{Dovepress}

4 published pages including figures, diagrams and references. The manuscript management system is completely online and includes a very quick and fair peer-review system, which is all easy to use. Visit http://www.dovepress.com/testimonials.php to read real quotes from published authors. 